\title{
The familial nature of rheumatoid arthritis
}

\author{
C M Deighton, D J Walker
}

Considerable emphasis is currently being placed on the immunogenetics of rheumatoid arthritis (RA). The observation that inherited factors are important in RA is by no means new, however. As far back as 1806 William Heberden in discussing 'chronical rheumatism' asked, 'Is this not in some degree hereditary?'. 'The first published attempt to answer this question was by Kroner in $1928,{ }^{1}$ who reported RA in four generations of women in one family. Like Kroner, all rheumatologists can quote families with a marked occurrence of RA. Yet a 1984 study concluded that 'familial aggregation of rheumatoid arthritis is weak'. ${ }^{2}$ How can these apparently contradictory observations be explained? How large is the genetic contribution to RA? What are the inherited susceptibility factors in RA? Why does RA seem to congregate in some families and not in others?

\section{Problems in interpreting RA family studies}

Rheumatoid arthritis family studies fall into two categories. The first are those studies that deliberately seek out multicase families. The main purpose of these studies is to determine whether genetic markers cosegregate with the presence of the disease, thus suggesting genetic linkage. The second are studies which attempt to establish the extent of the familial nature by avoiding any bias towards multicase families, so that, for example, disease concordance rates might be estimated in the families of all patients attending a rheumatology clinic, or in a defined community. Both types of study are essential to the understanding of the familial nature of RA.

Some ground rules for interpreting any $R A$ family study must be made in order to be able to compare and collate the data. This is particularly important in those studies estimating the extent of the familial nature of RA. Firstly, what is the method of ascertainment of the probands with RA in the study? Initial studies of families for any new genetic marker of a disease will usually be performed on hospital based populations for convenience. Caution is needed when interpreting disease concordance rates, however, as the source of ascertainment influences the estimates. Hospital based monozygotic twin concordance rates and sibling recurrence risks are both higher than those in community studies. ${ }^{13}$ Two major biases may account for this: concordant families attending hospitals increase their chances of ascertainment by a multiple of the number of affected subjects, and hospital patients may have more severe (and therefore more familial ${ }^{1}$ ) disease.
Secondly, how does the study define RA? Up to 1969 familial aggregation studies were based on the unsteady foundation of 'clinical' diagnostic criteria-that is, one researcher's opinion based on textbook descriptions of the disease. ${ }^{4-15}$ Little wonder therefore that these studies produced a range of $R A$ prevalence ratios (comparing disease in first degree relatives with that in controls) of 0.9 to $15 \cdot 2 .^{8}$ is The introduction of the American Rheumatism Association (ARA) criteria $^{16}$ strengthened the epidemiological base, but introduced new problems. Does the study include classical, definite, and probable disease? Or does it adopt a more black and white approach (as advocated by the updated ARA criteria ${ }^{17}$ ) at the risk of losing an indication of the heterogeneity of the disease? Does it consider seropositive or seronegative disease, or both, and radiologically erosive or nonerosive disease, or both? There is evidence that concordance rates are higher if the former categories are chosen in each case. ${ }^{1}$

Thirdly, how does the study consider the increase in RA prevalence over time-that is, some healthy subjects may go on to develop RA in the future. Although there is currently no way of identifying these subjects, simple information can provide an estimate of the size of the problem. For example, it would not be surprising to see significantly higher disease prevalence in the 80 than 20 year old relatives of affected subjects. Does the study give information on the age of the probands and their disease duration and if necessary attempt to control for these variables? A further reported problem is how to classify those subjects with a selflimiting form of RA, ${ }^{18}$ or 'previous' RA. ${ }^{19}$ Does the study identify these patients and what does it do with them?

As long as the label of ' $R A$ ' covers a markedly heterogeneous condition the best studies will break down familial aggregation data by method of ascertainment, diagnostic criteria, serology, radiology, and will consider the possible affects of time and disease severity on concordance rates. When all this information is provided, studies can be compared with confidence, and used to provide information on the influence of inherited factors on the presence and expression of RA.

How great is the genetic contribution to RA? In considering the genetic contribution to any disease a useful starting point is the disease concordance rate in monozygotic twins. Early twin studies, which did not define cases 
reliably, ${ }^{20}$ produced variable results, with a pooled average of $32 \% .^{1}$ The most recent hospital based study was the ARC twin study reported in $1970 .^{1}$ Thirty eight monozygotic twin pairs were examined, radiographed, and had rheumatoid factor titre assayed. Thirty per cent of seropositive erosive probands with RA had concordant twins. This figure is in contrast with a population survey in Finland, in which a national twin register was linked with a national sickness insurance register to produce a paired concordance percentage of just $12 \cdot 3 \%$. $^{3}$

The discrepancy between the concordance rates in these studies is not as great as it initially seems, as there are obvious differences between them. Firstly, the difference in ascertainment method, in that community based RA seems to be less familial than hospital ascertained RA. ${ }^{21}$ Secondly, record linkage to establish diagnosis in the Finnish study was less reliable than patient investigation and examination. Most importantly, however, the figure of $30 \%$ from the ARC twin study only included seropositive erosive disease, whereas the population survey included seropositive and seronegative probands in the $12 \cdot 3 \%$. If the seronegative twins in the ARC study are included the concordance rate drops to $15 \cdot 8 \%$, a figure much more comparable with the population data. Therefore monozygotic concordance rates for RA are not high. By comparison, the figure for insulin dependent diabetes mellitus (IDDM) is $36 \% .^{22}$ Given that monozygotic twins are more likely to share their environment and that this may artificially raise concordance rates, it seems that the genetic contribution to RA is low.

In agreement with this, the most valid studies on familial aggregation only show a small increase in risk to first degree relatives. ${ }^{15} 23-25$ The most recent population study estimates a typical prevalence ratio of 1.7 (95\% confidence limits 1.0 to 2.9 ) for first degree relatives compared with controls. ${ }^{2}$ In other words, if RA affects $1.5 \%$ of a population, and 100 patients with RA were ascertained from this population, only two or three patients would be expected to have first degree relatives with RA (though this figure may be higher in hospital based studies ${ }^{26}$ ). It also suggests that when two members of a family develop RA this may be because the disease is common. This argument is unacceptable, however, in those rare families in which healthy subjects are the exception and not the rule.

\section{What are the inherited susceptibility factors in RA?}

To understand why RA clusters in some families a review of the recent advances in immunogenetics is necessary. More is understood of the immunogenetics of IDDM than those of RA. This is probably because IDDM is more familial than RA, the disease starts earlier in life, ${ }^{27}$ and it is more likely to come to hospital attention because the consequences of non-treatment are life threatening. As both diseases are thought to be $T$ cell dependent autoimmune diseases, ${ }^{28} 29$ and they may occur together in the same families, ${ }^{30}$ it is informative to consider why
IDDM might cluster in some families, draw analogies with the RA data, and consider some of the unanswered questions.

There are strong associations between HLADR3, DR4 and IDDM, so that $95 \%$ of patients are DR3 or DR4 positive, or both. ${ }^{31}$ DR2 is negatively associated. ${ }^{32}$ HLA haplotype sharing of two, one, and no haplotypes would be expected to be $25 \%, 50 \%$, and $25 \%$ respectively in dually affected sib pairs if there was no linkage between HLA and IDDM susceptibility genes. The observed distribution is significantly different at $53 \cdot 6 \%, 39 \cdot 1 \%$, and $7 \cdot 3 \%$ respectively, ${ }^{27}$ suggesting that IDDM susceptibility genes are either very close to, or actually in, the HLA region. The sibling recurrence risk of IDDM is about $6 \%$, but siblings HLA-identical with the proband have a calculated and observed risk of $12.9 \%$, hemi-identical sibs $4.7 \%$, and non-identical sibs $1 \cdot 8 \%{ }^{27}$ The greatest risk of $19 \cdot 2 \%$ is in sibs sharing two haplotypes with a DR3/4 proband. ${ }^{27}$ Parental origin of the HLA haplotype is important in that there is a six times greater risk to children of an affected father than mother, even more marked with an inherited DR4 haplotype. ${ }^{31}$ The modes of inheritance are thought to be dominant-like in DR4 haplotypes in the absence of DR3, recessive-like in DR3 haplotypes in the absence of DR4, and a synergistic effect is thought to occur in the presence of both. ${ }^{27}$

The major histocompatibility complex (MHC) linked factor is more complex than a one locus, multiple allele model, however. NonDR HLA genes are also important-most notably, the presence of aspartate at position 57 of the first hypervariable region of the DQ $\beta$ chain protects from development of the disease. ${ }^{28}$ There is evidence that it is the $D Q$ subregion that is the main determinant of disease susceptibility, and that the positive associations between DR alleles and IDDM are due to linkage disequilibrium between DR and DQ. ${ }^{28}$ Examination of extended haplotypes discloses a possible role of class I alleles, so that HLA-B8 and B18, DR3, DQw2 haplotypes are found to be more predisposing. ${ }^{28}$ It has been estimated that the HLA region accounts for $60 \%$ of the genetic contribution to IDDM. ${ }^{33}$ Allotypes of non-HLA genes, such as Gm and insulin genes, are also associated with the disease. ${ }^{28}$

For RA there are strong associations in white patients with DR4 and to a lesser extent with DR1. ${ }^{34}$ About $20 \%$ of hospital based patients with RA are DR4 and DRI negative, however, so that the major DR associations as typed by conventional methodology are weaker in $R A$ than in IDDM. The subtypes, Dw4, 14, and 15 of DR4 are positively and DR2 and Dw10 negatively associated. ${ }^{35}$ HLA haplotype sharing of two, one, and no haplotypes deviates significantly from the expected values, though not as markedly as for IDDM $(38.6 \%, 46.6 \%$, and $14 \cdot 7 \%$ respectively). ${ }^{21}$ The sibling recurrence risk of $\mathrm{RA}$ is $4.9 \%$ in hospital based studies, ${ }^{21}$ and when these data are used HLA-identical siblings have a calculated risk of $7 \cdot 6 \%$, hemiidentical sibs $2 \cdot 1 \%$, and non-identical sibs $2 \cdot 9 \%$ (method described in ref 27). Our own recently 
completed study found a similar distribution of concordance factors in same-sexed sibships of $15 \cdot 5 \%, 7 \cdot 1 \%$, and $5 \cdot 2 \%$ respectively-that is, much higher concordance rates in HLA-identical siblings than in hemi-identical and nonidentical siblings (Deighton $\mathrm{C} \mathbf{M}$ et al, unpublished data). The relative risks of developing $R A$ by possession of different DR haplotypes are not available, though there is a higher prevalence of familial disease in DR4 probands. $^{36}{ }^{37}$ Multicase sibships of DR4 homozygous probands have a higher concordance rate than DR4 heterozygous probands, who in turn have a higher rate than DR4 negative probands (Deighton C $\mathbf{M}$, data in preparation). There is no information on whether parental origin of the HLA haplotype influences the presence of RA, though parental RA status does not seem to explain the genetic susceptibility to RA. ${ }^{38}$

The mode of inheritance of DR linked susceptibility is not as well reported as for IDDM. One study suggested dominant inheritance with low penetrance in most families, but recessive in a minority. ${ }^{39} \mathrm{~A}$ further study showed that affected offspring of DR4 heterozygotes were more likely to inherit HLA-DR4 than the non-affected offspring. ${ }^{38}$ Another study suggested dominant inheritance in DR4 families, with lower concordance rates for RA in DR4 negative pedigrees, but a higher prevalence of thyroid abnormalities. This study suggested that susceptibilty to RA in DR4 negative families with thyroid abnormality is non-HLA linked. ${ }^{40}$ The calculated sibling recurrence risks, with much higher rates in siblings sharing two than in those sharing one or no HLA haplotypes, suggest that both inherited haplotypes are important in the disease, which is more in keeping with a recessive mode of inheritance. Could it be that DR4 and non-DR4 linked susceptibility genes are inherited in a dominant and recessive-like fashion respectively?

Recent work states that the DQ locus is important in susceptibility to RA, in that DR4 DQw7 extended haplotypes are associated with the disease. Unlike IDDM, however, the DQ association seems to be secondary to DR. ${ }^{35}$ Associations with class III MHC genes and nonHLA genes, such as IgG heavy chain (Gm) and $\alpha_{1}$ antiprotease (PI), are weak and inconsistent, ${ }^{41-43}$ which is disappointing as it has been estimated that the HLA region only accounts for $37 \%$ of the genetic contribution to $R A .{ }^{21}$ Therefore there seems to be plenty of room in the human genome for other susceptibility genes, but what are the likely candidates? $T$ cell antigen receptors have crucial importance in terms of $T$ cell activation in the immune response, but work in this area is at an early stage. ${ }^{44}$ Of interest recently has been the suggestion that the light chain immunoglobulin $x$ genotype confers risk of RA among HLA-DR4 negative subjects. ${ }^{45}$ What is the mode of inheritance and mechanism of influence of the nonHLA genes?

Not only is HLA important in the presence of both RA and IDDM, it also influences disease expression. The same can also be said of the other important inherited factor in RA, which is female sex. In Bf-Fl (a class III MHC marker) positive, and HLA-DR3 positive DR4 negative subjects with IDDM, disease onset is more insidious. ${ }^{32}$ In RA the prevalence of DR4 is much higher in severe extra-articular forms of the disease such as Felty's syndrome and RA with vasculitis. ${ }^{46}$ Milder forms of RA as seen in the community may not be associated with DR4. ${ }^{47}$ There is increasing evidence that DQw7 is a marker of severe RA and Felty's syndrome, ${ }^{48} 49$ and it has been postulated that aspartate at position 57 of the $D Q \beta 1$ chain may predispose to severe RA (contrasting with the protection conferred in IDDM), though this requires confirmation. ${ }^{34}$ What is the mechanism for the marked heterogeneity of RA expression according to DR type? In extended haplotypes how do DQ alleles modify the presence and expression of RA? How do individual genes within the $M H C$ interact to confer susceptibility?

Although there is no sex association with IDDM, female sex must be included in any model explaining the cause of RA. The consistent prevalence ratio of women to men of $3: 1^{1}$ still requires explanation. Recently, we have shown that controlling for sex and HLA accounts for two thirds of the inherited risk in seropositive RA (Deighton C M et al, unpublished data), which is roughly equivalent to the estimated contribution of HLA to IDDM. Sex almost certainly influences disease expression in RA. There is evidence that disability may be greater in women with RA than in men, ${ }^{51}$ and that secondary Sjögren's syndrome is more common than in men. ${ }^{52}$ Conversely, men may be more prone to nodules ${ }^{53}$ and vasculitis. ${ }^{54}$ Is the influence of sex largely genetic, so that for example recessive alleles on the $\mathrm{X}$ chromosome might be important? Or is it predominantly sex differences in gene expression, immune response, or exposure to environmental agents?

Although familial and sporadic RA do not seem to be clinically or immunologically different diseases, ${ }^{36}{ }^{37}$ further work is needed to confirm this so that genetic data from multicase families can confidently be extrapolated to sporadic disease. Some studies have suggested that familial RA is more severe than sporadic RA, ${ }^{1}$ probably because HLA-DR4 predisposes primarily to the presence and severity of the disease, and secondarily to a familial propensity.

\section{Summary: Why does RA congregate in some} families?

To recap, recent RA familial aggregation and monozygotic twin studies, in which care has been given to disease definition, description, and method of ascertainment, have concluded that first degree relatives of probands with RA have no more than a slightly increased risk of developing the disease and that the genetic contribution to RA is not great. Perhaps 2 to $3 \%$ of probands with RA in the population have first degree relatives with $R A$, however, and in a small number of these families many subjects will be affected. To consider why RA clusters in these rare families the immunogenetics of IDDM have been compared with those of RA.

The available data suggest that RA multicase 
families are likely to be DR4 positive, to have a high proportion of siblings sharing both inherited HLA haplotypes with the proband, or to be those in which the HLA linked susceptibility gene seems to be dominantly inherited. In addition, women are likely to outnumber men in these families.

Information on the following is needed, however, to place the understanding of the familial nature of RA on a similar footing to that of IDDM: $(a)$ the relative risk of possession of different combinations of DR alleles; $(b)$ the mode of inheritance of non-DR4 DR susceptibility genes; $(c)$ the importance of extended HLA haplotypes, such as the DQ alleles; $(d)$ the role of female sex as a potential inherited susceptibility factor; and (e) the place of nonHLA genes, which must be important in RA.

When these gaps are filled we will be in a better position to identify those families that are particularly prone to $R A$, to understand why they develop it, and, armed with that knowledge, hopefully have a better chance in preventing it.

1 Lawrence J S. Rheumatoid arthritis-nature or nurture? Ann Rheum Dis 1970; 29: 357-79.

2 Deljunco D J, Luthra H S, Annegers J F, Worthington J W Kurland L T. The familial aggregation of rheumatoid arthritis and its relationship to the HLA DR4 association. Am $\mathcal{F}$ Epidemiol 1984; 119: 813-27.

3 Aho K, Markku K, Tuominen J, Kaprio J. Occurrence of rheumatoid arthritis in a nation

J Rheumatol 1986; 13: 899-902.

4 Lewis-Faning E. Empire Rheumatism Council report on an enquiry into the aetiological factors associated with rheumatoid arthritis. Ann Rheum Dis 1950; 9 (suppl 1): 1-94.

5 Barter R W. Familial incidence of rheumatoid arthritis and acute rheumatism in 100 rheumatoid arthritics. Ann Rheum Dis 1952; 11: $39-46$

6 Stecher R M, Hersh A H, Solomon W M, et al. The genetics of rheumatoid arthritis: analysis of 224 families. Am $\mathcal{~ H u m}$ Genet 1953; 5: 118-38.

7 Miall $W$ E. Rheumatoid arthritis in males: an epidemiological study of a Welsh mining community. Ann Rheum Dis 1955 14: $150-8$.

8 Neri Serneri G G, Bartoli V. Ricerche sui fattori ereditari del reumatisms cronico primario. Acta Genet Med Gemellol (Roma) 1956; 5: 402-10.

9 Seppa U. A study on the hereditary disposition to rheumatoid arthritis. Acta Rheumatologica Scandinavica 1957; 3: 92-100.

10 Lawrence J S, Ball J. Genetic studies in rheumatoid arthritis. Ann Rheum Dis 1958; 17: 160-8.

11 Bremner J M, Alexander W R, Duthie J J. Familial incidence of rheumatoid arthritis. Ann Rheum Dis 1959; 18: 279-84.

12 de Blecourt J J, Polman A, de Blecourt-Meindersma T. Hereditary factors in rheumatoid arthritis and ankylosing spondylitis. Ann Rherm Dis 1961; 20: 215-23.

13 Siegel M, Lee S L, Widelock D, et al. A comparative study of rheumatoid arthritis and systemic lupus erythematosus. N Engl F Med 1965; 273: 893-7.

14 Lawrence J S, Wood P H N. Genetics of rheumatoid arthritis. In: Duthie J $R \mathbf{R}$, Alexander $W \mathbf{R} M$, eds. Rhewmatic diseases. Baltimore: Williams and Wilkins, 1968 . $19-28$.

15 Schull $\mathbf{W}, \mathrm{J}$, Cobb S. The intrafamilial transmission of rheumatoid arthritis. III. The lack of support for a genetic hypothesis. I Chronic Dis 1969; 22: 217-22.

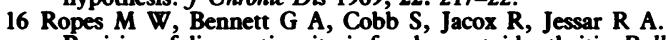
Revision of diagnostic criteria for rheumatoid arthritis. Bull Rhewm Dis 1958; 9: 175-6.

17 Arnett F C, Edworthy S M, Bloch D A, et al. The American Rheumatism Association criteria for the classification of Rheumatism Association criteria for the classification of

18 Silman A J. Epidemiological aspects of family studies in rheumatoid arthritis. Disease Markers 1986; 4: 55-8.

rheumatoid arthritis. Disease Markers 1986; 4: 55-8.
19 Walker D J, Griffiths I D. HLA associations are with severe heumatoid arthritis. Disease Markers 1986; 4: 121-32.

20 Meyerowitz S, Jacox R F, Hess D W. Monozygotic twin discordant for rheumatoid arthritis: a genetic, clinical and psychological study of 8 sets. Arthritis Rhewe 1968; 11 $1-21$

21 Deighton C M, Walker D J, Griffiths I D, Roberts D F. The contribution of HLA to rheumatoid arthritis. Clin Gene 1989; 36: 178-82.

22 Olmos P, A'Hern R, Heaton D A, et al. The significance of the concordance rate for type 1 (insulin-dependent) diabetes in identical twins. Diabetalogia 1988; 31: 747-50.

23 Veenhof-Garmann A M, Steiner F J, Westenhorp-Boerma F, et al. The prevalence of rheumatoid arthritis and rheumatoid factor in relatives and spouses of seropositive and seronegative patients suffering from definite or classical rheumatoid arthritis. In: Bennett P H, Wood P H N, eds. Population studies of the rheumatic diseases. New York: Excerpta Medica, 1968: 123-7.

24 Bennett P H, Burch T A. The distribution of rheumatoid factor and rheumatoid arthritis in the families of Blackfeet and Pima Indians. Arthritis Rhewem 1968; 11: 546-53.

25 Hellgren L. Inheritance of rheumatoid arthritis. Acto Rheromatologica Scandinavica 1970; 16: 211-6.

26 Wolfe F, Kleinheksel S M, Khan M A. Prevalence of familial occurrence in patients with rheumatoid arthritis. $\mathrm{Br} \mathcal{F}$ Rheumatol 1988; 27 (suppl 2(1)): 150-2.

27 Thomson G, Robinson $\mathbb{P}$, Kuhner $M$ K et al. Genetic heterogeneity, modes of inheritance, and risk estimates for a joint study of Caucasians with insulin-dependent diabetes mellitus. Am ₹ Hum Genet 1988; 43: 799-816.

28 Todd $\mathrm{J} \mathrm{A}$. Genetic control of autoimmunity in type 1 diabetes. Immunology Today 1990; 11 : 122-9.

29 Cooke T D, Scudamore R A. Studies in the pathogenesis of rheumatoid arthritis. 1. Immunogenetic associations. $\mathrm{Br} \mathcal{F}$ Rheumatol 1989; 28: 243-50.

30 Grennan D M, Sanders P A, Thomson W, Dyer P A. Rheumatoid arthritis: inheritance and association with other autoimmune diseases. Disease Markers 1986; 4: other autoi $157-62$.

31 Field L L. Insulin-dependent diabetes mellitus: a model for the study of multifactorial disorders. Am $\mathcal{F}$ Hum Genet 1988; 43: 793-8.

32 Gorusch A N. The immunogenetics of diabetes. Diabetic Medicine 1987; 4: 510-6.

33 Rotter J I, Landaw E M. Measuring the genetic contribution of a single locus to a multilocus disease. Clin Genet 1984; 26: $529-42$.

34 McCusker C T, Singal D P. Molecular relationships between the class III HLA antigens and susceptibility to rheumatoid arthritis. F Rheumatol 1988; 15: 1050-3.

35 Lanchbury J S S. Molecular genetics of the HLA-D region component of inherited susceptibility to rheumatoid arthritis. $\mathrm{Br} \mathcal{F}$ Rheumatol 1988; 27 : 171-5.

36 Sanders P A, Grennan D M, Dyer P A, Thomson W, de Lange G G. A comparison of clinical and immunogenetic features in familial and sporadic rheumatoid arthritis. features in familial and sporadi

37 Khan M A, Khan M K. HLA studies in familial and sporadic RA. Disease Markers 1986; 4: 67-76.

38 Silman A J, Hennessey E, Ditri M, Ollier W. Co-segregation of HLA and rheumatoid arthritis in multicase families. Tissue Antigens 1989; 33: 15-20.

39 Khan M A, Khan M K. Analysis of genetic susceptibility to familial RA. Disease Markers 1986; 4: 77-84.

40 Grennan D M, Sanders P A, Dyer P A, Harris R. HLA haplotype sharing by siblings with $R A$ : evidence for genetic heterogeneity. Ann Rheum Dis 1986; 45: 126-9.

41 Ollier $\mathbb{W}$, Thomson $\mathbb{W}$, Welch S, de Lange G G, Silman A. Chromosome 14 markers in RA. Ann Rheum Dis 1988; 47: 843-8.

42 Papiha S S, Pal B, Walker D J, Mangion P, Hossain M A. $\alpha_{1}$ Antitrypsin (PI) phenotypes in two rheumatic diseases: a reappraisal of the association of PI subtypes in rheumatoid reappraisal of the association of PI subtypes in
arthritis. Ann Rheum Dis 1989; 48: 48-52.

43 Dyer P A, Thomson W, Sanders P A, Grennan D M. Are major histocompatibility system class III products independent markers for susceptibility to RA? Disease Markers 1986; 4: 151-5.

44 Grennan D M, Dyer P A. Immunogenetics and rheumatoid arthritis. Immunology Today 1988; 9: 33-4.

45 Moxley G. Immunoglobulin kappa genotype confers risk of RA among HLA DR4 negative individuals. Arthritis Rheum 1989; 32: 1365-70.

46 Ollier W, Venables P J W, Mumford P A, et al. HLA antigen association with extra-articular RA. Tissue Antigens 1984; 13: 279-91.

47 De Jongh B M, Van Romunde L K J, Valkenberg H A, De Lange G G, Vanrood J J. Epidemiological study of HLA and $\mathrm{Gm}$ in rheumatoid arthritis and related symptoms in an and Gm in rheumatoid arthritis and related symptoms in an

48 Sansom D M, Amin S N, Bidwell J L, et al. HLA-DQ-related restriction fragment length polymorphisms in RA: evidence for a link

49 Stephens H A, Sakkas L I, Vaughan R W, et al. HLA-DQw7 is a disease severity marker in patients with RA. Immuno genetics 1989; 30: 119-22.

50 Singal D P, Reid B, Green D, Bensen W G, D'Souza M DNA restriction fragment length polymorphism of HLA DR2 haplotypes in normal individuals and in patients with rheumatoid arthritis. Ann Rheum Dis 1990; 49: 143-6.

51 Sherrer Y S, Bloch D A, Mitchell D M, Young D Y, Frie J F. The development of disability in rheumatoid arthritis. Arthritis Rheum 1986; 29: 494-500.

52 Whaley K, Williamson J, Chisholm D M, et al. Sjögren's syndrome. 1. Sicca components. $Q \mathcal{F}$ Med 1973; 42: $279-304$.

53 Kaye B R, Kaye R L, Bobrove A. Rheumatoid nodules. Review of the spectrum of associated conditions and a proposal of a new classification, with a report of four proposal of a new classification, with a report

54 Golding J R, Hamilton M G, Gill R S. Arteritis of rheumatoid arthritis. Br $\mathcal{Y}$ Dermatol 1965; 77: 207-10. 